\title{
Pertumbuhan Kebutuhan Pondok Pesantren Menggunakan Graph
}

\author{
Rizka Birthdayani Rodliata Rosida', Aulia Wahyu Hanifah², Faaula Dzurriyatul Adzkiya ${ }^{3}$, M. \\ Ainul Yaqin 4 \\ 1,2,3,4Teknik Informatika, UIN Maulana Malik Ibrahim Malang \\ Jl. Gajayana 50 Malang 65144, Telp: (0341) 551354 \\ 116650105@student.uin-malang.ac.id,216650026@student.uin-malang.ac.id, \\ 316650117@student.uin-malang.ac.id, 4yaqinov@ti.uin-malang.ac.id
}

\begin{abstract}
Islamic boarding school is one of the educational institutions in Indonesia as a means of learning Islam. Every Islamic boarding school in Indonesia has a different growth. The growth in the needs of Islamic boarding schools is strongly influenced by the number of new students enrolling, so it is necessary to plan and analyze the growth of the needs of Islamic boarding schools as a determinant of planning for further handling. This study aims to determine the growth of existing facilities in the boarding school in the specified operational standards. The stages of this research are knowing the history of Islamic boarding schools to determine the initial formation until they become qualified boarding schools, then we can draw a chart using Graphs to see the growing needs of each period. In the calculation, the AHP (Analytical Hierarchy Process) method also has a role to analyze the value generated from the Graph calculation as a benchmark for each growth period, so as to produce growth charts of the needs of Islamic boarding schools in each period. From this research, it can be used to actualize further business architecture.
\end{abstract}

Keywords: growth, AHP, Analytical Hierarchy Process, Islamic boarding school, Graph.

\begin{abstract}
Abstrak
Pondok pesantren merupakan salah satu lembaga pendidikan yang ada di Indonesia sebagai salah satu sarana pembelajaran agama Islam. Pada setiap pondok pesantren di Indonesia, memiliki pertumbuhan yang berbeda. Pertumbuhan kebutuhan pondok pesantren sangat dipengaruhi oleh jumlah santri baru yang mendaftar, sehingga diperlukan perencanaan dan analisis pertumbuhan kebutuhan pondok pesantren sebagai penentu perencanaan penanganan selanjutnya. Penelitian ini bertujuan untuk mengetahui pertumbuhan fasilitas yang ada dalam pondok pesantren tersebut dalam standar operasional yang ditentukan. Tahapan dari penelitian ini yaitu mengetahui sejarah dari pondok pesantren untuk mengetahui awal terbentuknya hingga menjadi pondok pesantren yang memenuhi kualifikasi, kemudian kita dapat melakukan penggambaran bagan menggunakan Graph untuk melihat pertumbuhan kebutuhan dari setiap periode. Tak hanya itu, dalam penghitungan Graph yang dilakukan metode AHP (Analytical Hierarchy Process) juga memiliki peran untuk menganalisis nilai yang dihasilkan dari penghitungan Graph sebagai tolak ukur setiap periode pertumbuhan, sehingga menghasilkan grafik pertumbuhan dari kebutuhan pondo pesantren pada setiap periode. Dari penelitian ini dapat digunakan untuk aktualisasi arsitektur bisnis selanjutnya.
\end{abstract}

Kata kunci: pertumbuhan, AHP, Analytical Hierarchy Process, pondok pesantren, Graph.

\section{PENDAHULUAN}

Pesantren sebagai lembaga pendidikan agama Islam lahir dan berkembang sejak masuknya agama Islam di Indonesia. Lembaga pendidikan ini pertama kali berdiri di Pulau Jawa pada masa Walisongo. Berdirinya pondok pesantren tidak bisa lepas dari kehadiran seorang kyai, dimana kyai tersebut telah tinggal selama bertahun-tahun untuk mengaji dan mendalami pengetahuan agama Islam. Hal tersebut membuat pertumbuhan pondok pesantren tidak lepas dari adanya 
pengakuan suatu lingkungan masyarakat terhadap kharismatik (kelebihan) seorang kyai dalam suatu keahlian (vak) tertentu beserta kesalihanya. Sehingga penduduk sekitar banyak yang datang untuk menuntut ilmu. Selain itu sosok kyai dalam suatu lingkungan atau desa merupakan cikal bakal dari lahirnya suatu desa. Lembaga pesantren dituntut memenuhi kebutuhannya di setiap periode dikarenakan dalam pertambahan santri mempengaruhi kebutuhan terutama fasilitas yang disediakan, sehingga dibutuhkan analisa yang mampu memaksimalkan pembangunan fasilitas di pondok pesantren. Dalam hal ini diperlukan penghitungan pertumbuhan kebutuhan pondok pesantren yang selama ini menggunakan Graph dengan metode Analytical Hierarchy Process (AHP) supaya dalam pertumbuhan kebutuhan pondok pesantren dapat terpantau dengan baik.

Pada tahun 2013, salah satu mahasiswa dari UIN Malang, Riza Kurniawan, melakukan penelitian terkait perancangan arsitektur bisnis terhadap Pondok Pesantren Salafiyah Syafi'iyah Situbondo menggunakan standar TOGAF. Penelitiannya memaparkan mengenai perancangan yang dibangun untuk melaksanakan sistem yang dibangun untuk pondok pesantren. Selain perancangan sistem yang akan digunakan, dilakukan juga analisis sistem yang dibutuhkan dan pendukungnya agar menunjang kinerja dari pondok pesatren tersebut. Dalam melakukan analisis kebutuhan sistem menggunakan metode TOGAF, analisis dimulai dari perencanaan hingga hasil inplementasi dari perancangan sistem dan melakukan perbandingan dengan sistem yang telah digunakan.

Penelitian tersebut hanya memaparkan mengenai kebutuhan sistem. Dalam implementasi kehidupan pondok pesantren, dibutuhkan beberapa perangkat pendukung aktivitas santri. Sehingga dalam perencanaan dan analisis kebutuhan pondok pesantren dibutuhkan sebagai penentu tujuan yang akan dicapai dan memastikan apakah sebuah pondok pesantren layak digunakan untuk kegiatan santri. Penghitungan pertumbuhan diperlukan agar skema yang dapat menentukan analisa secara pasti tergambarkan. Hal tersebut dapat dijelaskan melalui penggambaran Graph dengan kombinasi penghitungan menggunakan AHP untuk memperoleh grafik pertumbuhan kebutuhan pondok pesantren yang mudah dipahami.

\section{METODOLOGI PENELITIAN}

Dalam pengukuran pertumbuhan memerlukan berbagai kriteria, seperti halnya dalam menentukan kompleksitas melalui BPM yang telah dirancang. Sehingga arsitektur proses bisnis yang diinginkan dapat dilihat kadar efisiennya dalam periode pertumbuhan. Dalam perhitungannya kita menggunakan AHP, dimana dalam struktur organisasi terdapat deskripsi kerja dalam setiap bagian di dalamnya. Setiap deskripsi kerja mempunyai kebutuhan dalam pelaksanaannya. Kebutuhan-kebutuhan tersebut juga dapat dijadikan metrik pengukuran skala dan kompleksitas organisasi. Kebutuhan-kebutuhan tersebut meliputi bahan atau material, personil, peralatan, metode atau prosedur kerja, dan uang. Kebutuhankebutuhan tersebut merepresentasikan perencanaan produksi, sehingga pada setiap deskripsi kerja tersebut ada target kerjanya. Prosedur operasi baku merupakan salah satu komponen dalam perhitungan skala deskripsi kerja. Setiap 
deskripsi kerja memiliki prosedur operasi baku untuk melaksanakannya. Prosedur operasi baku direpresentasikan dalam bentuk model proses bisnis. Model proses bisnis dinotasikan dengan BPMN.

Sehingga skala dan kompleksitas untuk arsitektur bisnis dapat diukur melalui metrik-metrik yang didapatkan dari struktur organisasi dan model proses bisnis. Struktur organisasi seringkali direpresentasikan dalam bentuk tree. Metrikmetrik yang digunakan untuk mengukur skala dan kompleksitas struktur organisasi didapatkan melalui tree tersebut. Metrik-metrik tersebut adalah jumlah node, jumlah edge, kedalaman rata-rata (average depth), dan weight. Dengan metode AHP didapatkan formula skala dan kompleksitas struktur organisasi (OCscale).

$$
\text { oCscale }=\left(0.5 \cdot \sum \text { Node }\right)+(0.23 \cdot \text { Edge })+(0.17 \cdot \text { AverageDepth })+(0.055 \cdot \text { Weight })
$$

Representasi tree formula ini tergambar pada Gambar 1 berikut:

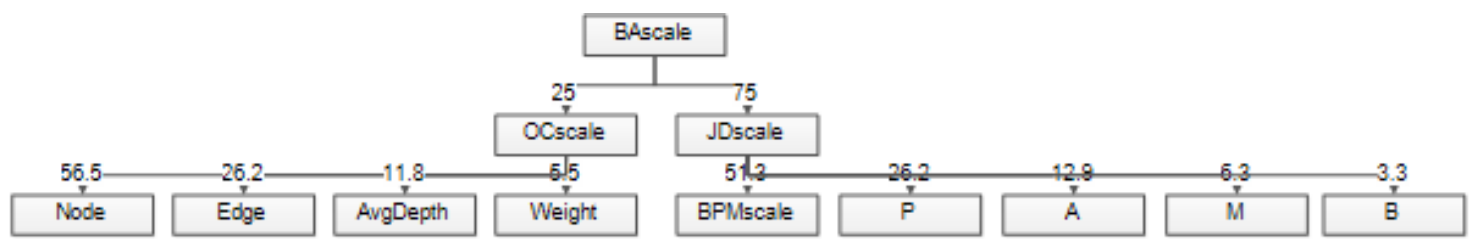

Gambar 1. Representasi tree formula

\section{HASIL DAN PEMBAHASAN}

Pengggambaran Graph dalam pemahaman model sangat diperlukan, seperti dalam menggambarkan pertumbuhan dari pertumbuhan kebutuhan yang terdapat pada pondok pesantren. Dalam setiap pertumbuhan pondok pesantren pasti memiliki tingkat kebutuhan yang berbeda, mulai dari kebutuhan yang sederhana sampai kebutuhan kompleks yang meliputi beberapa aspek. Pada tingkat pertumbuhan pertama, pondok pesantren masih dalam tahap pondok pesantren skala kecil yang dibangun dalam bangunan kecil, belum ada perluasan dan santri hanya berjumlah kurang lebih 20 orang santri. Kebutuhan pondok pesantren pada tahap pertama ini terdiri dari (1) akomodasi, yakni 2 kamar tidur, 3 kamar mandi, dan satu tempat belajar, serta (2) pengajar, yaitu 1 orang guru/kiyai. Gambar 2 menunjukkan penggambaran Graph sesuai dengan jumlah kebutuhan pondok pesantren tahap pertama dengan 14 node dan 13 edge. 


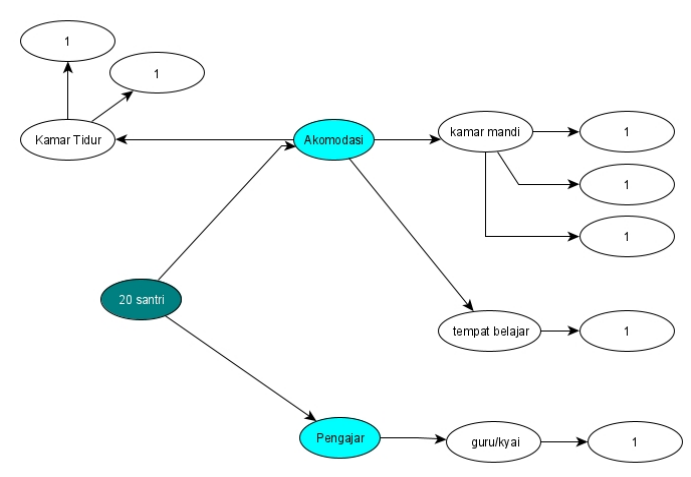

Gambar 2. Graph pertumbuhan pertama

Kemudian tingkat pertumbuhan kedua, pondok pesantren memiliki peningkatan jumlah santri menjadi kurang lebih 50 orang, maka pondok pesantren melakukan penambahan fasilitas serta memenuhi kebutuhan santri. Sehingga pertumbuhan pada tahap kedua yang terjadi pada pondok pesantren merupakan salah satu peningkatan kualitas dari aspek penanganan kesehatan santri yaitu unit kesehatan dan keamanan. Kebutuhan pondok pesantren pada tahap kedua ini digambarkan pada Gambar 3 menunjukkan Graph tahap pertumbuhan kedua yang terdiri dari 35 node dan 34 edge, di antaranya (1) akomodasi, yaitu 5 kamar tidur, 6 kamar mandi, dan 2 ruang kelas, (2) pengajar berjumlah 3 orang guru/kiyai, (3) keamanan berjumlah 3 orang petugas, serta (4) kesehatan, yaitu 1 ruang UKS beserta 3 orang petugas medis.

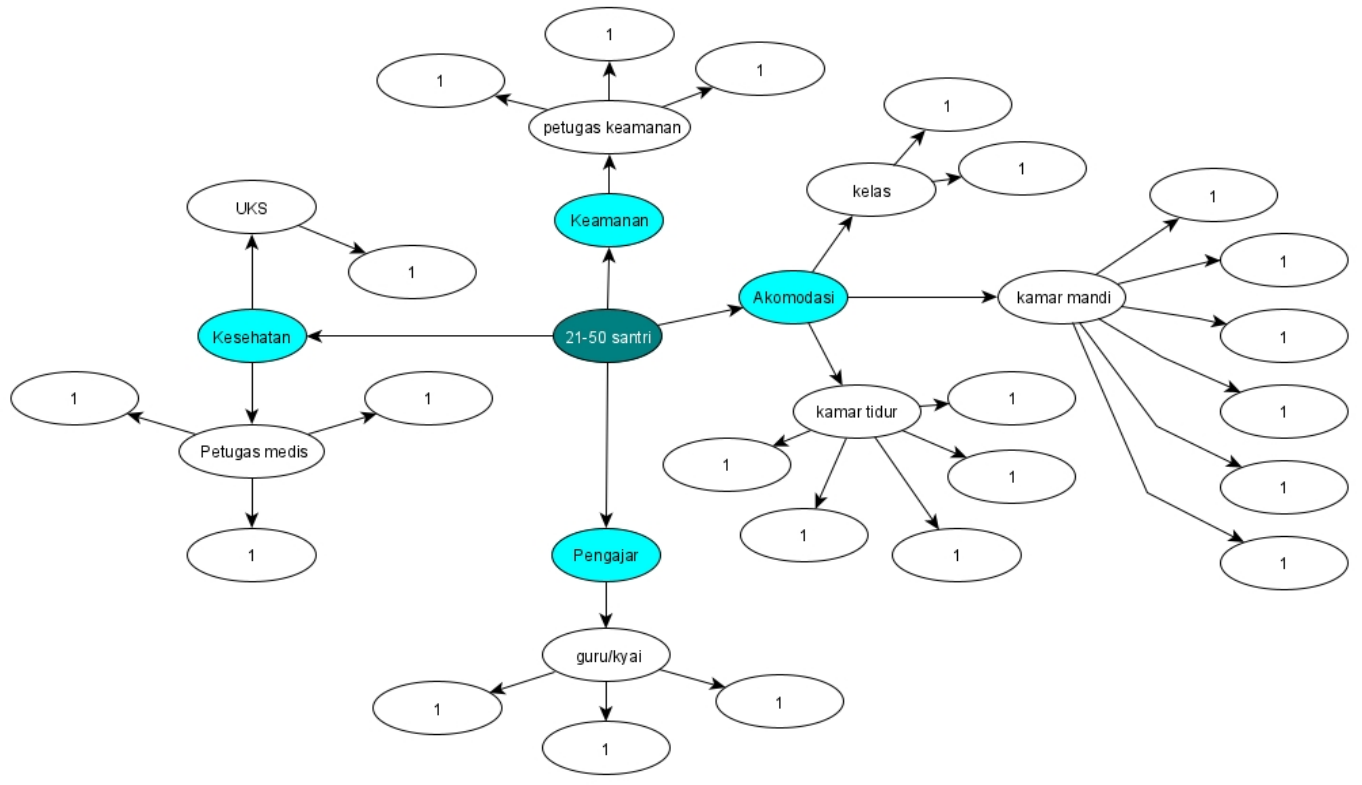

Gambar 3. Graph pertumbuhan kedua

Selanjutnya terjadi peningkatan jumlah santri menjadi kurang lebih 100 orang pada tingkat pertumbuhan ketiga. Maka pondok pesantren melakukan penambahan fasilitas serta memenuhi kebutuhan santri kembali yang meliputi pada setiap aspek yang telah ada dan disesuaikan pada jumlah santri. Fasilitas 
yang ada bertambah menjadi (1) akomodasi, yaitu 10 kamar tidur, 10 kamar mandi, dan 4 ruang kelas, (2) pengajar berjumlah 5 orang guru/kiyai, (3) keamanan berjumlah 6 orang petugas, serta (4) kesehatan, yaitu 1 ruang UKS beserta 6 orang petugas medis. Tahap pertumbuhan ketiga ini digambarkan pada Gambar 4 dengan 54 node dan 53 edge.

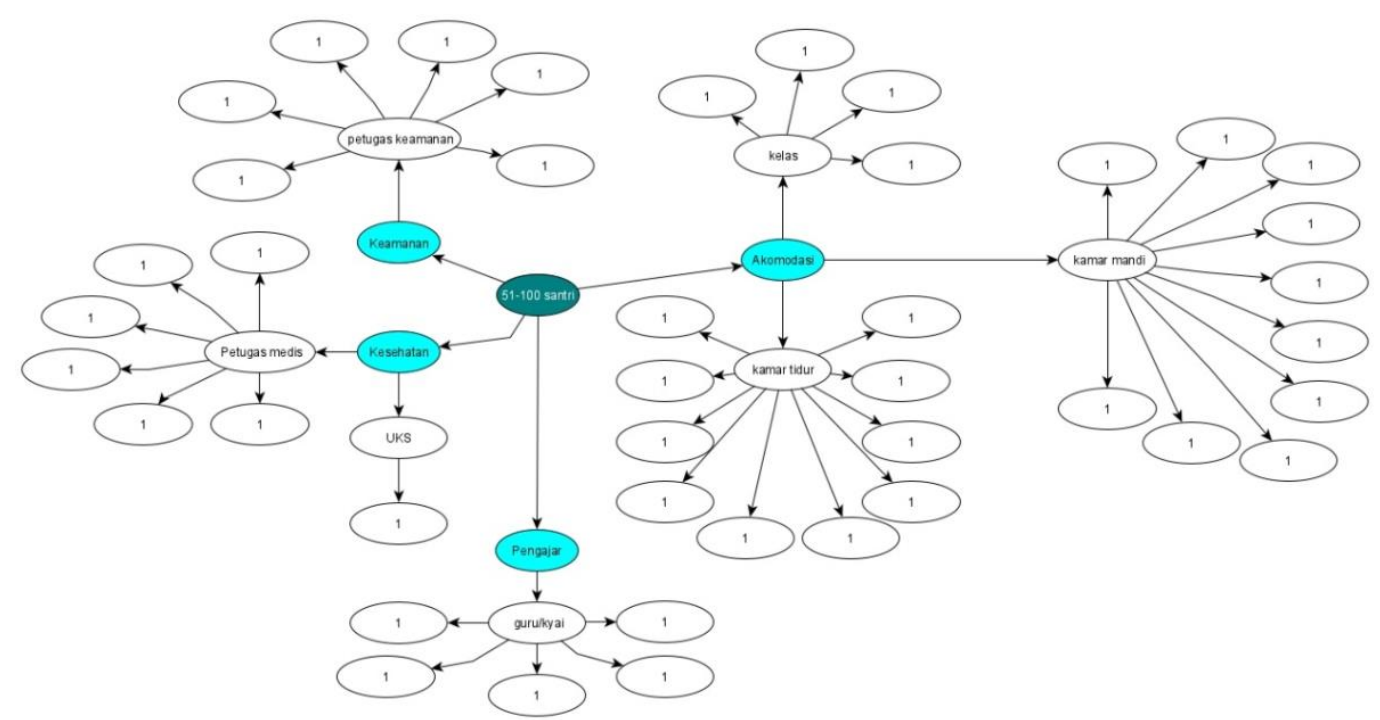

Gambar 4. Graph pertumbuhan ketiga

Tingkat pertumbuhan keempat, pondok pesantren memiliki peningkatan jumlah santri sebanyak kurang lebih 150 orang dan juga penambahan aspek agar kebutuhan santri tercukupi dalam lingkup asrama, di antaranya (1) akomodasi, yaitu 15 kamar tidur, 13 kamar mandi, dan 6 ruang kelas, (2) pengajar berjumlah 7 orang guru/kiyai, (3) keamanan berjumlah 10 orang petugas, (4) kesehatan, yaitu 1 ruang UKS beserta 8 orang petugas medis, serta (5) konsumsi yang terdiri dari 3 orang juru masak dan 2 orang pedagang. Tingkat pertumbuhan keempat digambarkan pada Gambar 5 dengan 80 node dan 79 edge. 


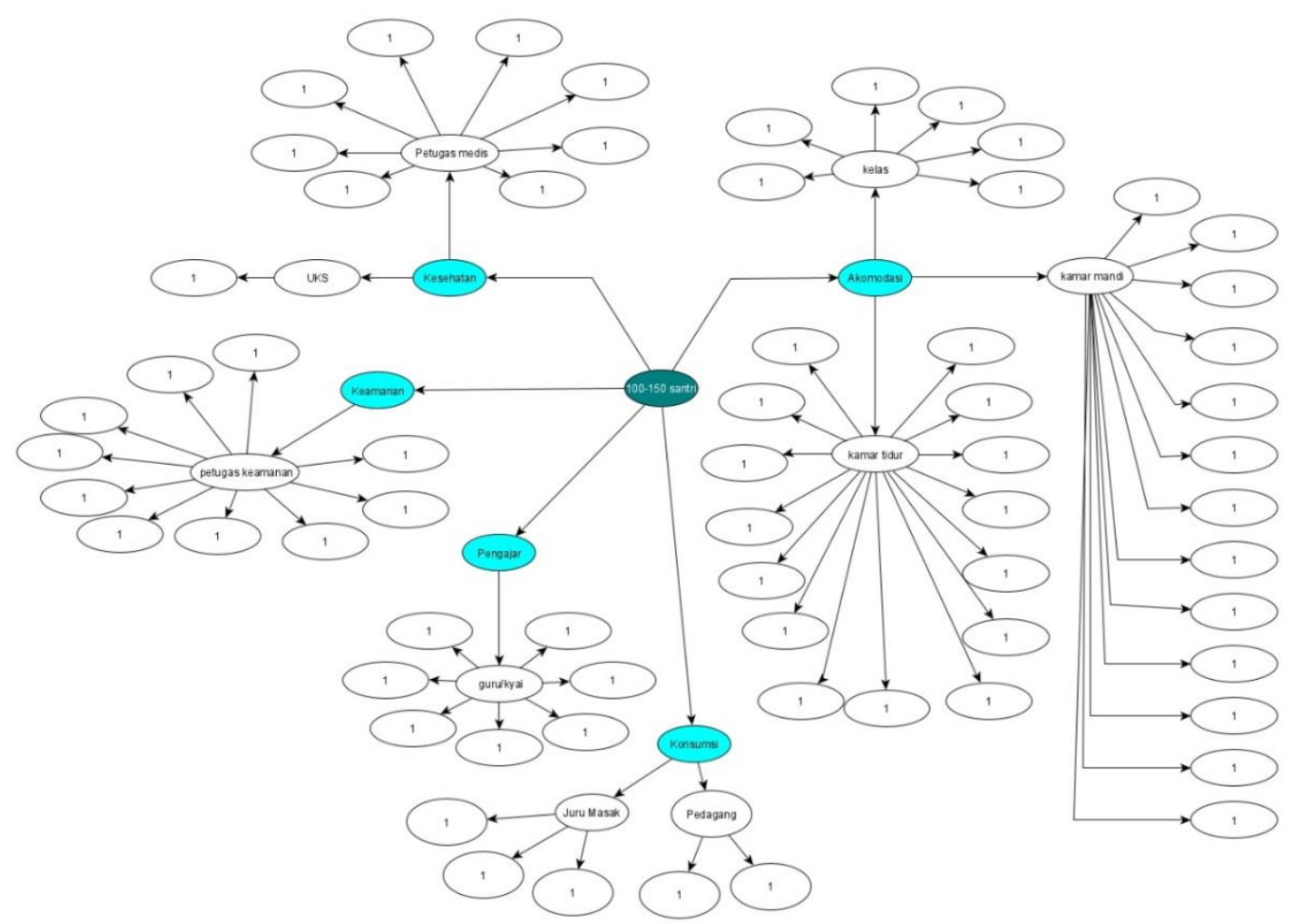

Gambar 5. Graph pertumbuhan keempat

Kemudian tingkat pertumbuhan kelima, terjadi peningkatan jumlah santri menjadi kurang lebih 200 orang sehingga penambahan fasilitas terjadi secara kompleks yang tergambar pada Gambar 6 dengan 101 node dan 100 edge, di antaranya (1) akomodasi, yaitu 20 kamar tidur, 20 kamar mandi, dan 10 ruang kelas, (2) pengajar berjumlah 9 orang guru/kiyai, (3) keamanan berjumlah 10 orang petugas, (4) kesehatan, yaitu 1 klinik dan 1 ambulans beserta 10 orang petugas medis, serta (5) konsumsi yanag terdiri dari 3 orang juru masak dan 2 orang pedagang. 


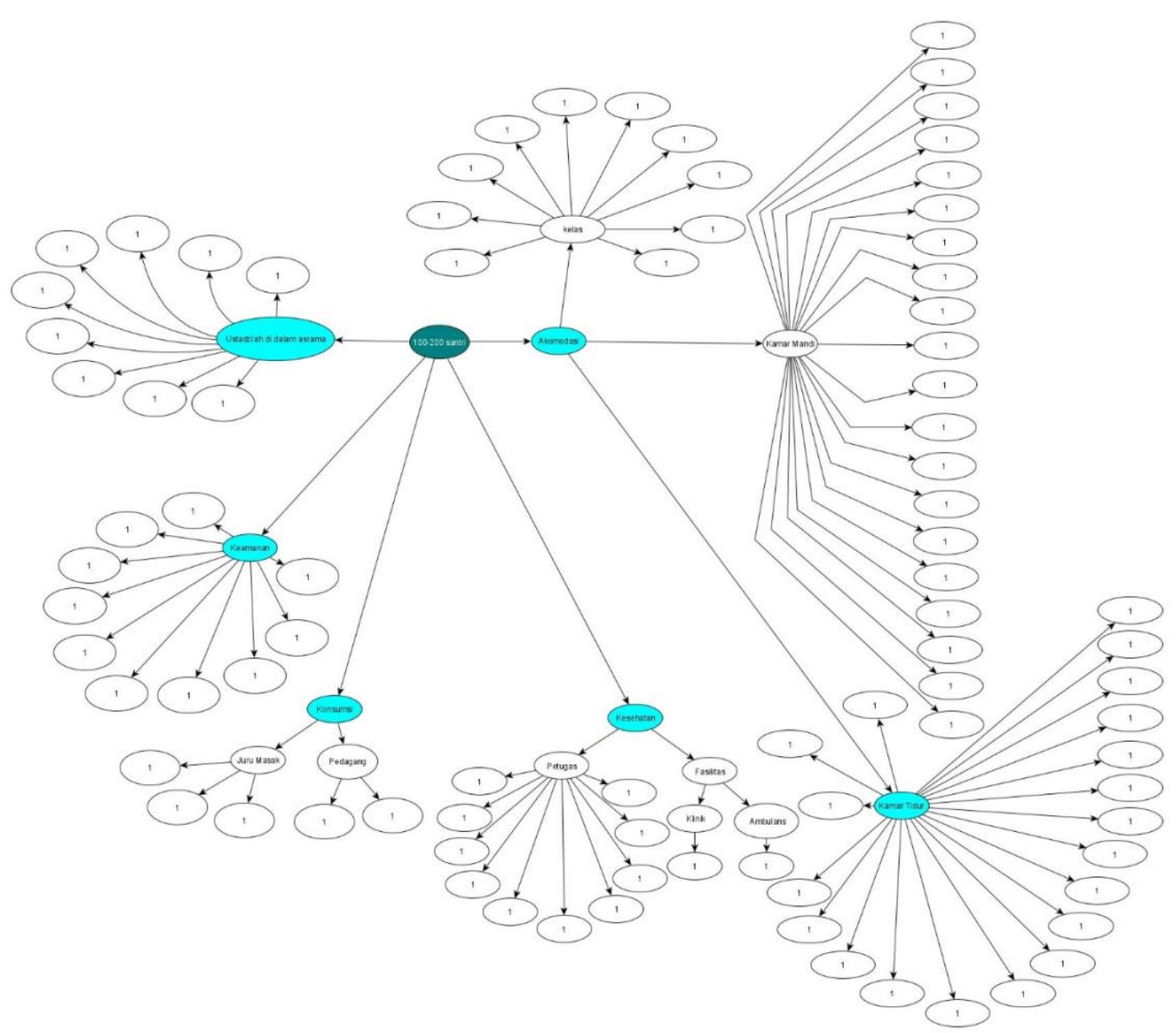

Gambar 6. Graph pertumbuhan kelima

Dari Graph teahap pertumbuhan pertama hingga yang terakhir, data pertumbuhan fasilitas yang terjadi dapat dirangkum dalam Tabel 1 berikut:

Tabel 1. Nilai Graph setiap pertumbuhan

\begin{tabular}{|c|c|c|c|c|c|}
\hline Pertumbuhan & 1 & 2 & 3 & 4 & 5 \\
\hline Siswa & 20 & 50 & 100 & 150 & 200 \\
\hline Kelas & 1 & 2 & 4 & 6 & 10 \\
\hline Guru & 1 & 3 & 5 & 7 & 9 \\
\hline Kamar Mandi & 3 & 6 & 10 & 13 & 20 \\
\hline UKS & - & 1 & 1 & 1 & - \\
\hline Petugas Medis & - & 3 & 6 & 8 & 10 \\
\hline Petugas Keamanan & - & 3 & 6 & 10 & 10 \\
\hline Kamar Tidur & 2 & 5 & 10 & 15 & 20 \\
\hline Klinik & - & - & - & - & 1 \\
\hline Ambulan & - & - & - & - & 1 \\
\hline Juru Masak & - & - & - & 3 & 3 \\
\hline Pedagang & - & - & - & 2 & 2 \\
\hline
\end{tabular}

Dari data pada Tabel 1 di atas, dapat dilakukan penghitungan pertumbuhan menggunakan AHP, dimana setiap pertumbuhan dipengaruhi oleh peningkatan siswa serta kebutuhan fasilitas yang digunakan, sehingga penghitungan nilai Graph 
dari setiap Node dan Weight memperoleh nilai OCscale yang dapat digunakan sebagai representasi nilai dari setiap periode pertumbuhan dan digunakan untuk mengetahui laju pertumbuhan yang terjadi pada pondok pesantren tersebut.

Tabel 2. Perhitungan nilai Ocscale

\begin{tabular}{|c|c|c|c|c|c|}
\hline Pertumbuhan & $\mathbf{1}$ & $\mathbf{2}$ & $\mathbf{3}$ & $\mathbf{4}$ & $\mathbf{5}$ \\
\hline Siswa & 20 & 50 & 100 & 150 & 200 \\
\hline Node & 14 & 35 & 54 & 80 & 101 \\
\hline Edge & 13 & 34 & 53 & 79 & 100 \\
\hline Average Depth & 1,9286 & 1,9714 & 1,9815 & 1,9875 & 2,01 \\
\hline Weight & 13 & 34 & 53 & 79 & 100 \\
\hline OCscale & 11.03286 & 27,52514 & 42,44185 & 62,85288 & 79,3417 \\
\hline
\end{tabular}

Dari perhitungan nilai OCscale pada Tabel 2, diperoleh grafik representative dari laju pertumbuhan yang terjadi pada pondok pesantren yang diikuti dengan faktor pertambahan fasilitas untuk memenuhi kebutuhan santri pada Gambar 7.

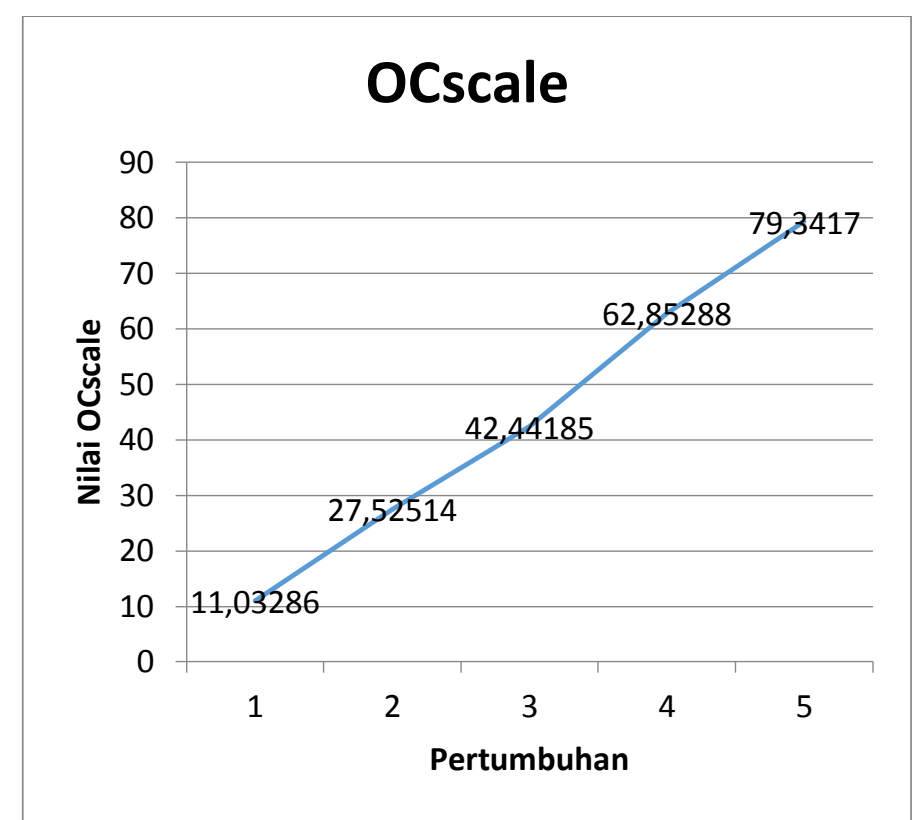

Gambar 7. Grafik laju pertumbuhan kebutuhan pondok pesantren

\section{SIMPULAN}

Dari hasil penelitian tersebut, diketahui bahwa pertumbuhan fasilitas dipengaruhi oleh beberapa faktor salah satunya adalah peningkatan jumlah fasilitas untuk memenuhi kebutuhan santri yang diterima setiap periode. Hal ini dapat dilihat pertumbuhan yang terjadi pada pondok pesantren setiap tahunnya semakin meningkat.

\section{DAFTAR PUSTAKA}

[1] Rachman, R., "Penerapan Metode AHP untuk Menentukan Kualitas Pakaian Jadi di Industri Garment”, Jurnal Informatika, Vol. 6, No.1, pp 1-8, April 2010. 
Jurnal Riset Sistem Informasi Dan Teknik Informatika (JURASIK)

Volume 5 Nomor 1 Februari, pp 7-15

ISSN: 2527-5771/EISSN: 2549-7839

http://tunasbangsa.ac.id/ejurnal/index.php/jurasik

[2] Herman, "Sejarah Pesantren di Indonesia", Jurnal Al-Ta'dib, Vol. 6, No. 2, pp 145-158. Juli 2013.

[3] Kuriawan, Riza, "Perancangan Arsitektur Enterprise pada Pondok PesantrenSalafiyah Syafi'iyah Situbondo dengan Standar TOGAF", Undergraduate thesis, Universitas Islam Negeri Maulana Malik Ibrahim. 2013. Diakses dari: http://etheses.uin-malang.ac.id/7612/

[4] Sidiq, U., "Pengembangan Standarisasi Pondok Pesantren", Nadwa,Jurnal Pendidikan Agama Islam, Vol. 7, No 1. (2013).

[5] Satyanuraga, D., "Penerapan Teori Graf Dalam Rencana Tata Ruang Kota". Makalah IF2120 Matematika Diskrit - Sem. I Tahun 2015/2016, (2015). 